\title{
Reliability of technical systems and the methodology for calculating MTBF using Flexsim computer simulation
}

\author{
Maciej Kubon ${ }^{1,2}$, Ireneusz Kaczmar ${ }^{1, *}$ and Pavol Findura \\ ${ }^{1}$ Institute of Technical Sciences, State Vocational East European Higher School in Przemyśl, Poland \\ ${ }^{2}$ Department of Production Organization, Logistics and Applied Computer Science, University of \\ Agriculture in Krakow, Poland \\ ${ }^{3}$ Slovak University of Agriculture in Nitra, Trieda Andreja Hlinku 609/2, 94976 Nitra-Chrenová, Slovak \\ Republic
}

\begin{abstract}
The paper focuses on computer modeling of the reliability of technical systems using FlexSim simulation software. It presents the theoretical foundations of machine reliability and principles of describing this phenomenon. The discussion demonstrates how to estimate the main parameters of reliability analysis - MTBF and MTTR. The end result was designing a simulation model and assessing the impact of machine failure on the productivity and performance of a technical system.
\end{abstract}

\section{Introduction}

According to the terminological standard PN-93/N-50191 [1], object reliability is "a set of properties that describe the readiness of the object and reliability, maintainability and maintenance support". This definition was supplemented by the comment that "the term reliability is used only for a general non-numerical description". The fact that the definition of reliability used characteristics, which are easily described numerically (quantitatively) in terms of values, particularly encourages the attempt to numerically describe the reliability of the exploited object. A closer look at the concept of reliability, in terms of operational analysis and technical design, requires the object of the research to be not only the object itself, but its operating system as well, including its reliability [2].

Reliability of machines, including vehicles, is an important factor influencing the effectiveness of system and process maintenance [3-4]. The phenomenon is widely described in the literature [5-6] using the general formula (1), where $f(x)$ is the probability distribution for breakdown.

$$
R(t)=P\{t \leq T\}=\int_{t}^{\infty} f(x) d x,
$$

The above dependence expresses the probability that the object, which started operation at the moment $t=0$, will not be damaged before the time $t \leq T$, where $T$ is the durability of the object. A number of statistical distributions can be used to describe the phenomenon of reliability. One of the most popular probabilistic models used to describe it is the model using exponential distribution. It is characterized by a property called memorylessness, i.e. the

\footnotetext{
*Corresponding author: i.kaczmar@pwsw.eu
} 
probability of the object's suitability does not depend on how much time has elapsed already. This approach assumes that an undamaged object is used as reliable as a new one. This model does not take into account changes occurring in the object as a result of adaptation and aging processes, e.g. as a result of fatigue, or loss of material. Objects to which exponential distribution can be applied are objects with purely accidental damage. It can be used if the following conditions are met:

- $\quad X$ it is the time (or distance) between events, with $X>0$;

- events are independent, i.e. the occurrence of one event does not affect the likelihood of the occurrence of another;

- the rate at which the events occur is similar throughout the range;

- two phenomena do not occur exactly at the same time.

In general, the exponential distribution is a continuous boundary distribution of the geometric spike. Its most important parameters are:

- density of the exponential distribution function (2),

$$
f(x)=\lambda e^{-\lambda x} \quad \text { dla } x \geq 0 ; \lambda \geq 0 ;
$$

where:

$\lambda$ is a parameter of the exponential function; it means the so-called arrival rate, i.e. the average number of occurrences of a given phenomenon per unit of time,

$e$ is the base of a natural logarithm, the Euler constant (with a value of 2.71...).

- Is mean and variance, expressed by the same formula (3),

$$
\mu=\frac{1}{\lambda} ; \quad \sigma^{2}=\frac{1}{\lambda}
$$

- Is the cumulative exponential distribution function (4),

$$
F(x)=1-e^{-\lambda x} \quad \text { dla } x \geq 0 ;
$$

Assuming that the frequency of failure is described by the negative exponential distribution, the formula for reliability of a technical object has the form (5):

$$
R(t)=e^{-\lambda t} \quad \text { dla } \quad t \geq 0 ; \lambda \geq 0 ;
$$

where $\lambda$ is a constant failure rate. An example description of the reliability of a technical object using exponential distribution is shown by the formula (6); this equation means that the machine will fail once every 100 units of machine time.

$$
R(t)=e^{-0,01 t} \quad \text { gdzie } \quad \lambda=0,01 ;
$$

For example, if the manufacturer declares that the intensity of damage of a combine harvester is $\lambda=10^{-4}\left(\mathrm{~h}^{-1}\right)$. And if the probability of trouble-free operation of the harvester is to be calculated for 1000 hours, then the value of the reliability function for $t=1000$ (h) is: $R(1000)=e^{-0,0001 \cdot 1000}=e^{-0,1}=0,9048$. In this case, there is over 90 percent chance that the harvester will operate correctly for 1000 hours.

In computer simulation models, technical and organizational measures are often used to describe the phenomenon of reliability. The measures are estimated on the basis of interviews with plant personnel, empirical observations or data provided by the manufacturer of a particular machine. The most important parameters include:

- First Time Failure - the average time until the first failure occurs;

- MTBF (Mean Time Between Failures) - the average time between successive failures; this parameter determines for how long, on average, the machine works properly 
before going into the next failure. In other words, MTBF is the time span between the moment of resuming work after a failure, and the next failure. This parameter is determined by various methods, but most often it is based on empirical observations of the production process.

- MTTR (Mean Time To Repair) - the average repair time, which comprises realizing the fact that the machine has failed, calling maintenance, and the time of the repair itself. The MTTR table specifies how long a damaged machine, or group of machines remains in a failure condition before resuming operation. One MTBF/MTTR table can be defined for one machine, or a group. Relationships that exist between MTBF and MTTR are shown in Fig. 1.

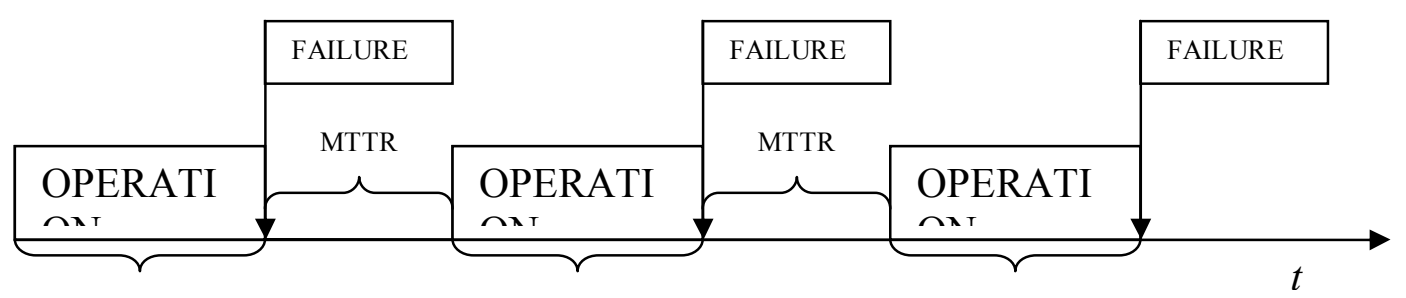

MTBF

MTBF

MTBF

Fig. 1. Relations between MTBF and MTTR parameters

- Down Function informs the system what status the object is to take when going into failure; by default it is machine stop.

- Resume Function informs the system what status the object is to take when resuming operation after the failure.

Methods for calculating the value of MTBF using statistical distributions can be found in the literature [7]. The most useful are: exponential distribution (7), Weibull distribution (8) and normal distribution (9).

$$
\begin{gathered}
M T B F_{\text {exp }}=\frac{1}{\lambda}, \\
M T B F_{w b}=\gamma+\eta \Gamma\left(1+\frac{1}{m}\right), \\
M T B F_{\text {normal }}=\mu,
\end{gathered}
$$

The total reliability of a technical system depends on the reliability of all its components, as well as the configuration of connections between individual machines. If the elements are connected serially (Fig. 2), reliability of the system decreases. This is because the system built of serial elements only functions when all individual machines are operational [5,8]. If the reliability of a single machine is $R$, and the number of machines is $n$, the reliability of the entire linear system is described by the formula (10). However, for a parallel system (Fig. 3), reliability increases as more machines are added, and it is described with the formula (11). 


\section{$\mathbf{R} 1 \rightarrow \mathbf{R} 2 \rightarrow \mathbf{R} \ldots \mathbf{n} \rightarrow$}

Fig. 2. Serial connection of elements in a technical system

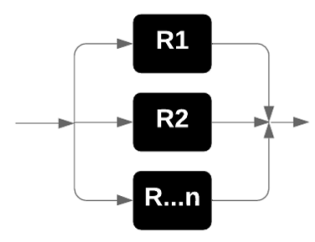

Fig. 3. Parallel connection of elements in a technical system

$$
\begin{gathered}
R_{S}=R^{n} \\
R_{S}=1-\left(1-R^{n}\right)
\end{gathered}
$$

Based on formulas (10) and (11), there is a number of possibilities to calculate the reliability of mixed objects composed of serial and parallel elements (Fig. 4). Reliability of a mixed object (Fig. 4) can be calculated using the formula (12).

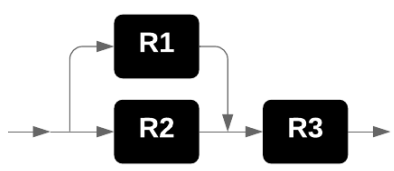

Fig. 4. Mixed connection of elements in a technical system

$$
R_{S}=1-\left(1-R^{n}\right) \cdot R
$$

Methods for calculating more complex technical systems are widely described in literature [3,5,9-11].

\section{Testing the reliability of selected technical systems using a simulation model}

The purpose of the test is to check the impact of machine failure rate on the productivity of the technical system in three different configurations: A, B, C. The three simulation models were designed in the FlexSim program environment (Fig. 5): A - serial, B - parallel, C mixed. Standard objects from the FlexSim library were used to build them, i.e. machines of the same type (Processor), sources of parts for machine processing (Source) and the final object where the flow elements are utilized (Sink). Input parameters are common to all machines in the three configurations tested, and are as follows:

- $\quad$ sources enter the production system in an unlimited number, with zero delay time; the time of entry of the source into the system determines the efficiency of the first machine;

- the processing time on all machines is 6 minutes;

- the failure rate of all machines is described by an exponential distribution in the range from $\lambda=10^{-1}\left(\mathrm{~h}^{-1}\right)$ to $\lambda=10^{-4}\left(\mathrm{~h}^{-1}\right)$;

- machine time in jammed/failure state is distributed with an even distribution within the range from 8 to 24 hours;

- total simulation clock time: 40 hours per week 4 weeks per month 6 months $=$ 960 hours, which yields half a year of work of a technical system; 
- neither the distance between machines, nor additional time for scheduled maintenance and periodic inspections were taken into account;
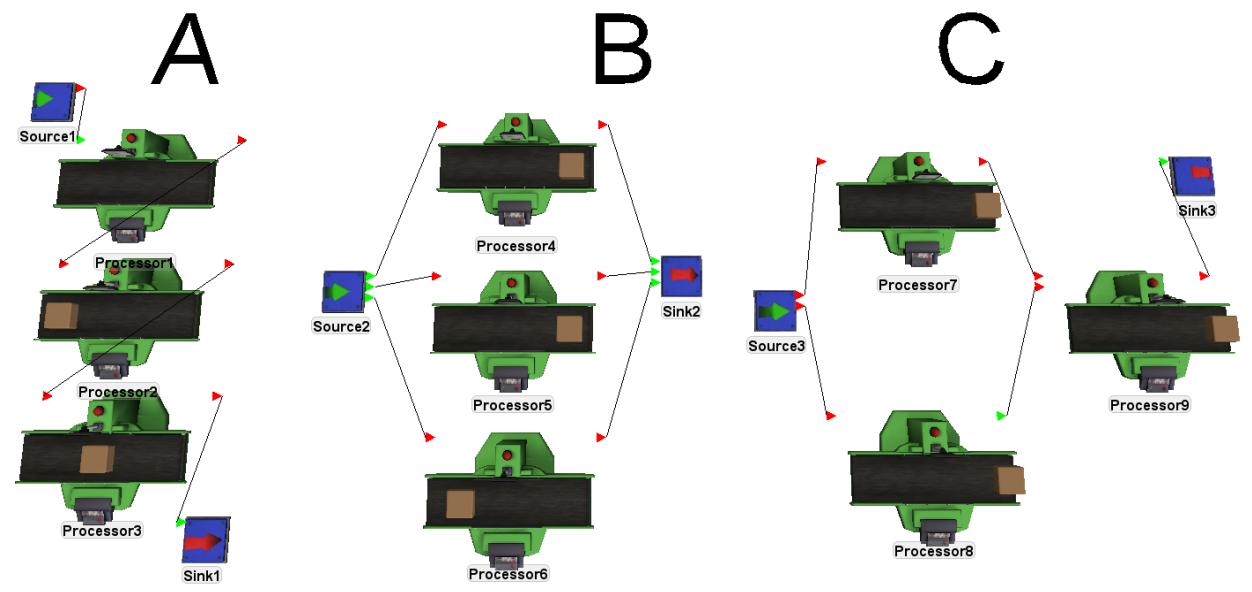

Fig. 5. Simulation models: A - serial, B - parallel, C - mixed

Machine reliability parameters described with the factor $\lambda$ were defined in intervals in the global table, which is the source of input data for the simulation experiment. Four simulation experiments were carried out, with ten replications for each scenario. The first scenario refers to the parameter $\lambda=10^{-1}\left(\mathrm{~h}^{-1}\right)$, and similarly, the last, fourth one relates to the reliability of the machines at the level $\lambda=10^{-4}\left(\mathrm{~h}^{-1}\right)$, which corresponds to one failure per ten thousand hours of work in exponential distribution. For each configuration: A, B, C, the average percentage of time for a group of machines in a failure was examined, in relation to the overall simulation clock time. The results are shown in figures 6,7 and 8 . Below each of the figures are calculations regarding system performance. For each failure scenario, the number of items that could be produced by each system was calculated.

\section{Average breakdown group A}

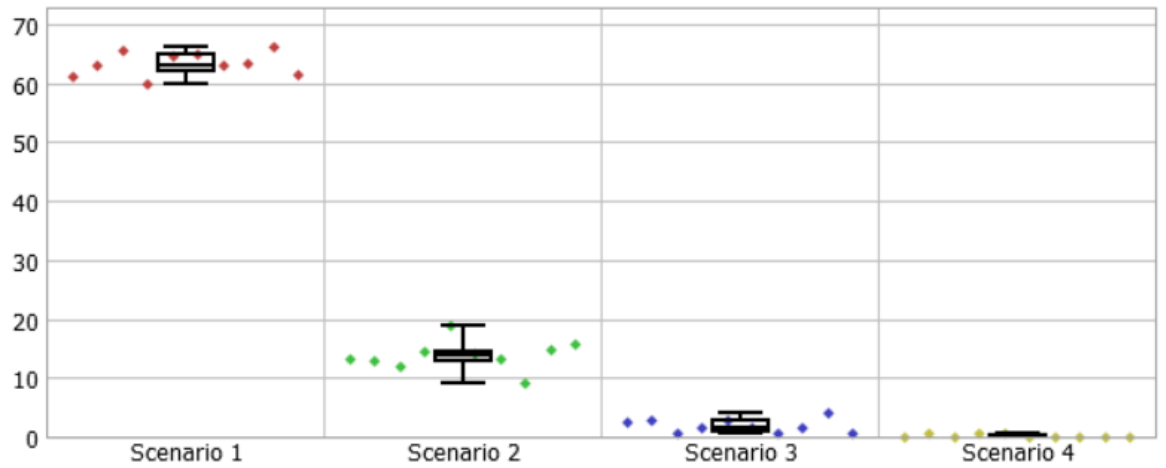

Fig. 6. The average percentage of time in a failure state for system A

The number of products that can be manufactured by system A, for individual failure scenarios, is calculated below. 
Total number of products model A

\section{Mean (90\% Confidence)}

Scenario 1

Scenario 2

Scenario 3

Scenario 4
$428<486<543$

$5701<6058<6415$

$8887<9064<9240$

$9492<9543<9594$
Sample Std Dev

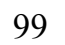

615

304

88
Min Max

$376 \quad 687$

$5033 \quad 7214$

$8479 \quad 9424$

$9380 \quad 9597$

\section{Average breakdown group B}

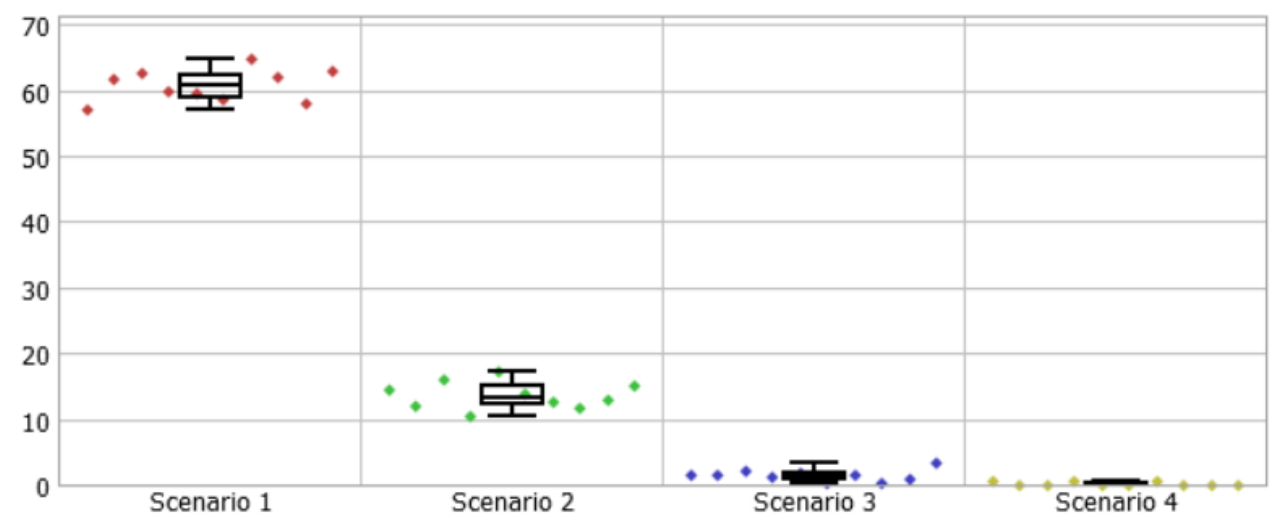

Fig. 7. The average percentage of time in a failure state for system B

The number of products that can be manufactured by system B, for individual failure scenarios, is calculated below.

Total number of products model B

$\begin{array}{lllllll}\text { Scenario 1 } & 10894 & <11305 & <11715 & 709 & 10127 & 12312 \\ \text { Scenario 2 } & 24502 & <24855<25209 & 610 & 23817 & 25766 \\ \text { Scenario 3 } & 28227 & <28371<28516 & 249 & 27830 & 28693 \\ \text { Scenario 4 } & 28695 & <28744<28794 & 86 & 28594 & 28797\end{array}$




\section{Average breakdown group C}

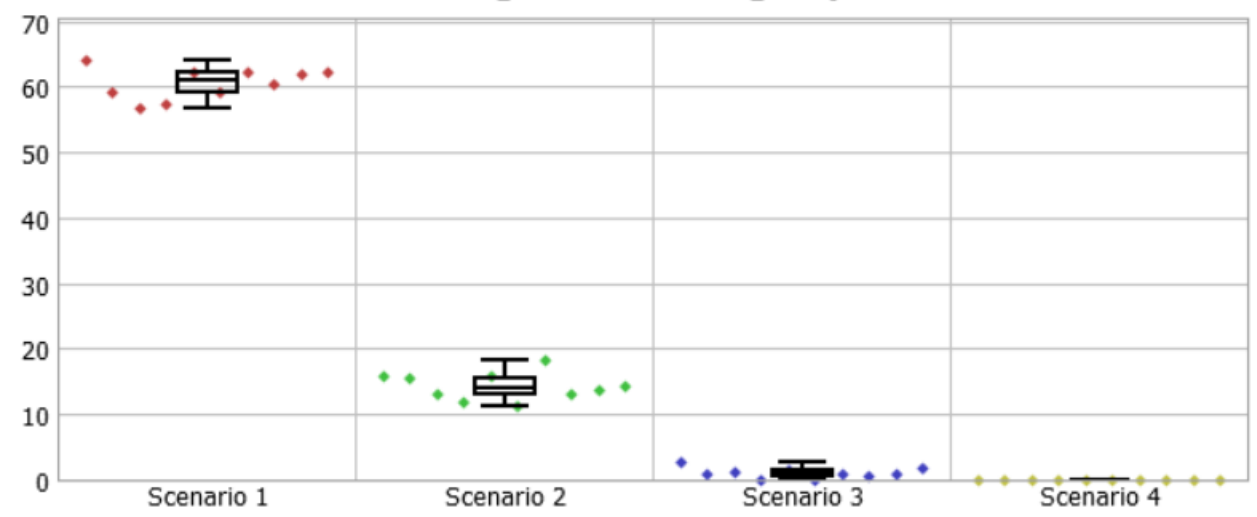

Fig. 8. The average percentage of time in a failure state for system $\mathrm{C}$

The number of products that can be manufactured by system $\mathrm{C}$, for individual failure scenarios, is calculated below.

Total number of products model $\mathrm{C}$

\begin{tabular}{|c|c|c|c|c|c|c|c|c|}
\hline & \multicolumn{5}{|c|}{ ivean (9070 cominuence) } & Sample sta ver & I 13 & \\
\hline Scenario 1 & 2163 & $<$ & 2395 & $<$ & 2627 & 400 & 1805 & 2985 \\
\hline Scenario 2 & 7844 & $<$ & 8074 & $<$ & 8304 & 397 & 7554 & 8626 \\
\hline Scenario 3 & 9411 & $<$ & 9495 & $<$ & 9578 & 144 & 9236 & 9598 \\
\hline Scenario 4 & $\mathrm{~N} / \mathrm{A}$ & $<$ & 9598 & $<$ & $\mathrm{N} / \mathrm{A}$ & 0 & 9598 & 9598 \\
\hline
\end{tabular}

\section{Conclusions}

Computer modeling works well as a tool for testing the performance of technical systems. In the analyzed cases, the highest reliability of the entire production system was obtained for the fourth simulation scenario, regardless of the configuration of machines in the system. Productivity for individual configurations varied, but in general it was also the highest in the fourth scenario. For configurations $\mathrm{A}$ and $\mathrm{C}$, the productivity for the fourth scenario was close to the maximum productivity possible, without failure of any of the machines, i.e. 9600 pcs. However, for configuration $\mathrm{B}$, the maximum theoretical productivity without failure should be three times higher than for configuration A, but similar results were obtained.

\section{References}

1. Słownik terminologiczny elektryki. Niezawodność. Jakość usługi. PN-93/N-50191.

2. Bezpieczeństwo funkcjonalne elektrycznych/elektronicznych/programowalnych elektronicznych systemów związanych z bezpieczeństwem. Część 5: Przykłady metod określania poziomów nienaruszalności bezpieczeństwa. PN-EN 61508-5:2005.

3. Z. Kowalczyk, M. Cupiał, Estimation methods of the agricultural equipment value with regard to evaluation of Alina carrot harvester. Contemporary Research Trends in Agricultural Engineering BIO Web Conf., 10 (2018).

4. E. Popardowski, D. Kwaśniewski, Technical-Economic Aspects Of The Eradication Of Energy Willow Plantations, in: Proceedings of 24th International PhD Students Conference 
(MendelNet 2017) / Cerkal Radim [et al.] (ed.), Mendel University, ISBN 978-80-7509529-9, 808-813, (2017).

5. E. Macha E, Niezawodność maszyn, Oficyna Wydawnicza PO, (2001).

6. A. Loska, Komputerowo zintegrowane zarządzanie, 2, 37-46, (2011).

7. Y. Liu, J. Fan, Y. Li, One system reliability assessment method for CNC grinder. Eksploatacja i Niezawodność, 16 1, 97-104, (2014).

8. A. Gola, Eksploatacja i niezawodność, 90, (2019).

9. L. Będkowski, T. Dąbrowski. Podstawy eksploatacji: Podstawy niezawodności eksploatacyjnej. Wojskowa Akademia Techniczna, (2006).

10. M. Kuboń, I. Kaczmar, Studies \& Proceedings of Polish Association for Knowledge Management, 85, (2017).

11. I. Kaczmar, Komputerowe modelowanie i symulacje procesów logistycznych $w$ środowisku FlexSim, PWN, Warsaw, (2019). 